DOI: $10.22616 /$ REEP.2020.019

\title{
Students' Perceptions about Using Background Music in Music Lessons
}

\author{
Ligita Stramkale Dr.paed. \\ University of Latvia, Latvia \\ ligita.stramkale@lu.lv
}

\begin{abstract}
This paper determines students' perceptions about the use of background music in music lessons while performing written tasks. The aim of the study is to demonstrate the perceptions of the students in grades 2-3 about the impact of background music on their well-being while performing written tasks and the quality of their performance in the music lesson. Previous studies on the impact of background music on learning outcomes and behaviours have been analysed, and an empirical study has been conducted to achieve the aim of this study. The empirical study involved 78 primary school students $(N=78)$ in grades 2-3. The study was carried out at X comprehensive school between September and November 2019. To determine the students' perceptions about the impact of background music on well-being and the quality of performance, each student had to complete a written task while playing background music. After completing the task, each student was asked to fulfil self-assessment questionnaire. The study found that the majority of students have a positive attitude towards background music. However, it was also found that the background music creates a very bad mood for some students, which in turn negatively affects their well-being. Background music can help students to feel more comfortable during performing a written task if the music can calm them down and/or stimulate them to work. The study shows that students evaluated the fact that background music can help them performing written task qualitatively was at an average level. Students believe that background music can help them complete the task successfully, if it affects their mood positively, promotes concentration and stimulates them to work. It is also found that some students had a very positive attitude towards background music, and in contrasts, some students had a very negative attitude towards it. Although one student likes background music very much, it could be very disturbing for another one at the same time. This study identified a variety of views, which is to a large extent based on the individual characteristics of each student.
\end{abstract}

Keywords: background music, music lesson, primary school student, school education.

\section{Introduction}

We often hear the background music in different life situations and places, cafes, shopping malls, lounges, Hotel lobbies or on the radio. The music is playing, but, in fact, we are not really listening to it. The background music is music to be played while doing various activities such as shopping, reading, driving, or cleaning home, and it should have a sound level of lesser than 60 decibels. The background music should not interfere with accomplishing the mission, and it must be inconspicuous and imperceptible. Background music can be used in a variety of ways: it could generate a sense of calmness or stimulate a person to do something as well as help to concentrate or to relax.

The educational process at school should be carried out in a safe, motivating and creative environment. Music is one of the tools that help create the appropriate environment. Background music can be played at school during breaks and lessons. For example, in music lessons students acquire some skills in singing and playing percussive instruments, they actively listen to music and learn music theory. Along with creative activities, students perform a variety of written tasks in workbooks. Most of the written tasks are related to increasing the ability to learn rhythm and sheet music. At the same time, there are also some tasks in which students have the opportunity to express themselves by using colours. It is possible to involve background music while performing both written and creative tasks given in music lessons. However, the teachers` attitude towards the use of background music during classes is mixed. This is also proved by a study conducted in South Korea and England in 2017 (Lee, Welch, 2017), which determined the teachers ' perspectives on background music as an accompanying element of child`s play. It was found out that $54 \%$ of teachers have a positive attitude towards background music as they believe that background music can create an appropriate environment for learning. But $46 \%$ of teachers think that background music only makes extra noise in the classroom. 
Teachers' ambiguous attitude towards the use of background music in the teaching process is also proved by some studies that identified the benefits and disadvantages of background music. Romanian researchers D. Jucan and A. Simion believe that background music can have both positive and negative effect on children. Their study identified the role of background music in the development of social-emotional competence in preschool children. Social-emotional development is determined based on five social-emotional abilities: trust, perseverance, organisation, understanding, and emotional strength. The researchers conclude that background music positively influences the assimilation of new information, the development of children behaviour, and the social interaction among children. It was found out that the background music has negatively affected the activities, which are applied in the study (Jucan, Simion, 2015). However, the positive effect of background music has been identified by several researchers. For example, D.L. Strachan, who carried out a study with Montessori educational institutions for children aged three to six, found that as a result of background music (instrumental, slow and quiet music was played), children smile more, talk, and were more productive (Strachan, 2015). The positive effect of background music is also highlighted by K.N. White, who studied the productivity, motivation and behaviour of primary school students. The study found that implementing classical background music in the classroom, increased students' motivation to learn, improved the ability to concentrate on the task, and developed positive behaviour. K.N. White believes that background music has a positive impact not only on each child but also on the class as a whole (White, 2007).

Two studies proved that background music has a positive impact on the retention and reproduction of information. The first study (Abdolmanafi-Rokni, Ataee, 2014) was conducted with students aged 7 to 11 , who learn English as a foreign language. The study found that background music promoted vocabulary recall and retention, positively influenced students' motivation to learn English, and helped them paying attention to the teacher. The second study (Lehmann, Seufert, 2017) involved college students and intended to find out how background music affects learning a visual text. To measure learning outcomes the ability to recall and comprehend the text was examined. The study determined that the higher the working memory capacity, the better students learned with background music. Background music can be used to improve students' skills. For example, A. Sevan' study used the orchestra's performance of Mozart's music to improve the coordination skills of children with emotional and behavioural difficulties. The study concluded that Mozart's music performed by an orchestra was capable of improving the coordination of students, reducing their frustration and anxiety, as well as reducing aggressive behaviour (Savan, 1999).

Many researchers are interested in the influence of background music on students' learning achievement in mathematics and languages. There is no doubt that the results of these studies are contradictory. A study conducted by S.P. Hallam, J. Price and G. Katsarou analysed the influence of soothing and relaxing music on the performance of students aged 10 to 12 in mathematics and found out that this music has a huge impact on the performance of mathematics tasks. Background music creates a mood rather than directly influencing students' cognitive processes (Hallam, Price, Katsarou, 2002). A similar result was obtained by A.S. DeMers, who investigated the effect of background music on reading comprehension. The study involved fifth-grade students, who were divided into an experimental group and a control group. The experimental group performed a reading comprehension test with background music, but the control group without. The experimental group had a better performance than the control group. As a result of the study, it is concluded that performing a test causes anxiety among students and the background music can both reduce the anxiety and increase the test scores (DeMers, 1996).

Background music is sometimes unable to increase the test scores, as revealed by M. Manthei and S.N. Kelly while studying the impact of popular and classical music on the mathematics test scores. The researchers concluded that background music has no statistically significant impact on math test scores (Manthei, Kelly, 1999). On the contrary, H. Cho in 2005 was able to prove that background music had a positive effect. The students participated in the study wrote an argumentative essay with and without background music. It was found that high tempo dance music helped students to concentrate and reduced pauses during writing, which also led to faster essay writing (Cho, 2015).

Many teachers, who decide to use background music in class, may have several questions related to it. What style of music is appropriate to be background music? How loud, fast or rhythmic should the music be? M. Griffin believes that it is better to choose instrumental music. Vocal music with a fast tempo accelerates the heart rate, and music with lyrics requires more cognitive effort. The louder is the music in the background, the more distracting it becomes. When choosing the right music for background, it should be taken into 
consideration that the music of a major tonality is happier and more positive than minor music (Griffin, 2015). H.H. Decker-Voigt thinks that it is important to consider the popularity of the background music because that could reduce response to the music or on the contrary increase it (Decker-Voigt, 1991).

Although several studies (Jucan, Simion, 2015; DeMers, 1996; White, 2007) have proved the positive influence of playing classical music in the background on student's achievement and the formation of positive behaviour, popular music may also be a good means of improving student's learning achievement. A. Rauduvaite considers that popular music plays a prominent role on the educational value of music, provides a positive emotional experience and can serve as a meaningful tool for promoting values among primary school students (Rauduvaite, 2018). Furthermore, E.A. Szentgyorgyi's study found that $67 \%$ of students believe that background music did not interfere with concentration, and even positively influenced their achievement in reading. In addition, the study found that playing popular music in the background improved students' reading performance more than classical music (Szentgyorgyi, 2015). It has to be admitted that the music played in the background can be very diverse and even the smallest musical nuance can have a negative impact on the learning process. For example, researchers A.C. Chen and C.S. Wen conducted a study to determine the impact of background music styles on mathematical computation and reading comprehension. College students were involved in this study. Three different styles of music were used as background music: soft music, rock music and heavy metal music, at the same time, mathematical computation and reading comprehension were also tested without background music. The study found that the style of background music had no significant impact on mathematical computation and reading comprehension. However, the study found a different impact of background music styles on men and women. The women performed mathematical computation equally well with all styles of music played in the background, while men performed better with soft music in the background. Furthermore, the study participants pointed out that their concentration was negatively affected by the noisy strong beats in rock and roll and heavy metal (Chen, Wen, 2015).

Although there are several studies have been recently carried out to identify the impact of background music on learning achievement in mathematics and languages, there is still no study to read about the impact of using background music during the music lesson. Someone maybe thinks that there is no need to use background music in the music lesson, as it contains enough musical activities, but it is essential to find out the opinion of the students themselves on this issue. This also determined the aim of the study.

The aim of the study is to demonstrate the perceptions of the students in grades 2-3 about the impact of background music on their well-being while performing written tasks and the quality of their performance in the music lesson.

\section{Methodology}

The participants were $78(\mathrm{~N}=78)$ primary school students in grade 2 and 3 . The study was conducted within the framework of the music lesson and took place at $\mathrm{X}$ general education school from September to November 2019. The study seeks to answer the following three research questions.

- How can the use of background music affect student well-being in the music lesson?

- What are the students' perceptions about the impact of background music on the quality of performing written tasks?

- What is the students' attitude towards listening to background music while completing written tasks in the music lesson?

In order to answer the study questions, $2^{\text {nd }}$ and $3^{\text {rd }}$ grade students were asked to complete a written task from the music workbooks. This task for students in both classes was at the same level of difficulty and related to sheet music learning. The students performed the task in ten minutes, during which the Baroque composer A. Vivaldi's autumn, part 1, Allegro from the concert series "Four seasons" was played in the background. Vivaldi's concert series "Four seasons" is a programmatic piece of music, which spreads happiness among students through representing the peasants' joy during harvest celebrations in autumn, which included dances and songs. The students had previous experience of performing written tasks with background music, in which fragments of Vivaldi's concert series "Four seasons" were also used.

After completing the task, each student was asked to fulfil a self-assessment questionnaire consisting of thirteen statements. Each of the statements had to be evaluated by students using a 4-point Likert scale. The 
self-assessment questionnaire was anonymous and there was no time limit for completion. For data processing, the response variants were recoded into digits: 4 - agree, 3 - partially agree, 2 - partially disagree and 1 - disagree. To determine the students' perceptions of the quality of the task, the 4 points on the Likert scale were divided into three levels. Low level if the arithmetic mean is between 1.00 and 2.00, medium level is between 2.01 and 3.00 and high level between 3.01 and 4.00. The statements used in the study were divided into three groups. The first group of statements determined the students' perception of well-being. The second group of statements determined the students' perception of the quality of performing the task. The third group of statements determined the attitude of students towards background music.

The Statistical Package for Social Science was used to analyse the collected data. Arithmetic mean $(M)$, standard deviation $(S D)$, standard deviation error $(S E)$ and median $(M d n)$ are calculated for each statement in the study. The asymmetry factor was used to determine the normality of each variable (Skewness). Skewness between -0.5 and 0.5 means that the obtained data is fairly symmetrical, between -1 and -0.5 , or 0.5 to 1 , means that the data is moderately skewed, and if the data is less than -1 or greater than 1 , then it is highly skewed. The Bivariate (Pearson) correlation analysis was used to examine the reliability of the responses. The correlation coefficient has statistically significant sigma of 0.01 and 0.05 .

\section{Results and Discussion}

The well-being of a student in a music lesson is very important to develop a sense of satisfaction. Teaching methods and techniques implemented in the classroom must give the student a pleasant feeling. The sounds of music are an integral part of many students' daily life and create an internally good feeling. But what about music in the background when you have to perform written tasks during the music lesson. Does it help to create well-being? Or is it a disturbing factor anyway? The results obtained are shown in Table 1.

Table 1

Student well-being

\begin{tabular}{|l|c|c|c|c|c|c|}
\hline \multicolumn{1}{|c|}{ Statements } & $\boldsymbol{M}$ & $\boldsymbol{S D}$ & $\boldsymbol{S E}$ & $\boldsymbol{M d n}$ & Skewness & Skewness $\boldsymbol{S D}$ \\
\hline Background music makes me feel positive & 3.43 & 0.74 & 0.08 & 4.00 & -1.48 & 0.27 \\
\hline Background music helps me focus & 3.08 & 1.08 & 0.12 & 3.00 & -0.93 & 0.27 \\
\hline Background music relaxes me & 3.23 & 1.10 & 0.12 & 4.00 & -1.12 & 0.27 \\
\hline Background music calms me down & 3.35 & 0.93 & 0.10 & 4.00 & -1.36 & 0.27 \\
\hline Background music stimulates me & 2.92 & 1.11 & 0.12 & 3.00 & -0.65 & 0.27 \\
\hline
\end{tabular}

The study found that the majority of students agree with the statement "Background music makes me feel positive" (Table 1). At the same time, the scores of median and Skewness (Mdn=4.00; Skewness $=-1.48$ ) show that the data obtained is highly skewed, which indicates that playing music in the background severely hindered some students while performing the written task.

Similar results were obtained in the other two statements: "Background music relaxes me" $(M=3.23$; $S D=1.10)$ and "Background music calms me down" $(M=3.35 ; S D=0.93)$. Most students agree or partially agree with both statements. However, these two statements are also asymmetrical. This indicates that although most students considered that background music was able to relax them and calm them down during the performance of the task, it was clear that some students could not relax $(M d n=4.00$; Skewness $=-1.12)$, or calm down $(M d n=4.00$; Skewness $=-1.36)$. The study found that the background music, which can calm students down $(r=0.29 ; p<0.01)$ or stimulate them to work $(r=0.29 ; p<0.01)$ can also make them feel positive.

Most students partially agree that background music helps them focus on performing the task $(M=3.08$; $S D=1.08$ ). Students may find it difficult to focus on a task if it is too complicated for them. The study found a correlation between the ability to concentrate and the music playing in the background while performing written tasks $(r=0.52 ; p<0.01)$. Students think that background music does not hinder their concentration $(r=0.37 ; p<0.01)$ and they want the teacher to use background music in the class $(r=0.33 ; p<0.01)$. A slightly smaller number of students think that background music can stimulate them $(M=2.92$; $S D=1.11)$. The study found that students who believe that background music stimulates them to work also think that it does not interfere with their written tasks $(r=0.45 ; p<0.01)$. Also, M.V. Zilgalve believes that 
background music can have a positive or negative effect on the human nervous system, emotions and thinking. The effect of background music increases if it does not sound all the time and the psychologist recommends choosing instrumental compositions to be played in the background (Zilgalve, 2003).

In almost every music lesson, students perform tasks from the music workbook for a certain period of time. The tasks included in the music workbook enable students to better understand sheet music as well as develop the ability to identify the means of musical expression and musical instruments in the compositions. The students usually do notation-related tasks in silence. But what if the music teacher turned on background music at this time? This study determines the students' perceptions about the impact of background music on the quality of performing written tasks. The results obtained are shown in Table 2.

Table 2

The quality of performing written tasks

\begin{tabular}{|l|c|c|c|c|c|c|}
\hline \multicolumn{1}{|c|}{ Statements } & $\boldsymbol{M}$ & $\boldsymbol{S D}$ & $\boldsymbol{S E}$ & Mdn & Skewness & Skewness SD \\
\hline Background music helps me complete the task & 2.79 & 1.18 & .13 & 3.00 & -.44 & .27 \\
\hline $\begin{array}{l}\text { Background music hinders me from completing } \\
\text { the task }\end{array}$ & 1.93 & 1.15 & .13 & 1.00 & .80 & .27 \\
\hline $\begin{array}{l}\text { Background music has a positive impact on the } \\
\text { quality of performing the task }\end{array}$ & 3.07 & 1.02 & .11 & 3.00 & -.89 & .27 \\
\hline $\begin{array}{l}\text { Background music has a negative impact on the } \\
\text { quality of performing the task }\end{array}$ & 1.71 & 1.00 & .11 & 1.00 & 1.22 & .27 \\
\hline $\begin{array}{l}\text { The performance quality of the task is not } \\
\text { affected by background music }\end{array}$ & 2.28 & 1.23 & .14 & 2.00 & .24 & .27 \\
\hline
\end{tabular}

Most students partially agree with the statement "Background music helps me complete the task" $(M=2.79 ; S D=1.18)$. At the same time, quite a lot of students partially disagree with the statement "Background music hinders me from completing the task" $(M=1.93 ; S D=1.15)$. The study determines that background music helps students to complete the task if it can positively affect their mood $(r=0.32$; $p<0.01)$, helps them to concentrate $(r=0.52 ; p<0.01)$ and stimulates them to work $(r=0.37 ; p<0.01)$. It is just as important for students that background music not only prevents them from completing written tasks $(r=0.71 ; p<0.01)$, but also it should be able to encourage them to perform the task successfully $(r=0.38 ; p<0.01)$. In general, students evaluated at a medium level the fact that background music can help them perform written tasks in music workbooks. It is possible that students would evaluate the impact of background music on other types of activities at a high level. There are many activities, in which background music could be integrated. For example, C.W. Gillespie and K.R. Glider have found that teachers use background music during learning academic and social skills, as well as arranging their place after some activities or preparing for some new activities (Gillespie, Glider, 2010).

The majority of students partially agree with the statement "Background music has a positive impact on the quality of performing the task" ( $M=3.07 ; S D=1.02)$. Students partially disagree with both statements "Background music has a negative impact on the quality of performing the task" ( $M=1.71 ; S D=1.00)$ and "The performance quality of the task is not affected by background music" ( $M=2.28 ; S D=1.23)$. The students believe that background music can influence the quality of performing the task positively if it is positive $(r=0.34 ; p<0.01)$ and if it is not disturbing $(r=0.38 ; p<0.01)$. In general, the students evaluated at a medium level the fact that playing background music during music lesson has a positive impact on the quality of performing written tasks. It should be mentioned that the results obtained are only applied to music subject because other school subjects may show a different trend. For example, C.W. Davidson and L.A. Powell studied the impact of background music on task performance and concluded that background music positively influences task performance (Davidson, Powell, 1986).

The study found that the impact of background music on the performance quality of a written task is largely determined by the individuality of each student. The same background music can help one student perform the written task correctly $(r=0.29 ; p<0.01)$ but also can disturb another student $(r=0.34 ; p<0.01)$. The role of students' individual characteristics in the influence of background music has also been identified in several studies. For example, G. Cassidy and R. MacDonald investigated how background music affects introverted and extroverted students when they performing a cognitive task and concluded that in the presence of background music, compared to performing tasks in silence, the performance of cognitive tasks decreases for both introverts and extroverts (Cassidy, MacDonald, 2007). A study 
conducted by A. Furnham and L. Strbac identified introverted and extroverted reference while performing reading comprehension task, prose recall task and mental arithmetic task. This study also found that the task performance with background music was worse than performing it in silence. Furthermore, this was more noticeable for introverted students than for extroverted students (Furnham, Strbac, 2002).

The third statements group intended to determine students' attitude towards playing background music in music lesson while performing written tasks. The attitude describes the student's ability to evaluate the possibility of integrating background music in the music lesson. The results obtained are shown in Table 3.

The study shows that most students partially agree with the statement "I want background music to be played while performing written tasks" $(M=3.05 ; S D=1.21)$. The scores of median and skewness $(M d n=4.00$; Skewness $=-0.76$ ) indicate that the data obtained are moderately skewed, which give in turn the opportunity to conclude that some students have a very strong positive attitude towards background music. A similar trend was also found regarding the statement "I do not want background music to be played while performing written tasks" ( $M=1.94 ; S D=1.22)$. The scores of median and skewness $(M d n=1.00$; Skewness $=0.75)$ indicate that the data obtained are moderately skewed, which lead us to conclude that some students have a very strong negative attitude towards background music (Table 3 ).

Table 3

Attitude towards background music

\begin{tabular}{|l|c|c|c|c|c|c|}
\hline \multicolumn{1}{|c|}{ Statements } & $\boldsymbol{M}$ & $\boldsymbol{S D}$ & $\boldsymbol{S E}$ & $\boldsymbol{M d n}$ & Skewness & Skewness SD \\
\hline $\begin{array}{l}\text { I want background music to be played while } \\
\text { performing written tasks }\end{array}$ & 3.05 & 1.21 & .13 & 4.00 & -.76 & .27 \\
\hline $\begin{array}{l}\text { I do not want background music to be played while } \\
\text { performing written tasks }\end{array}$ & 1.94 & 1.22 & .13 & 1.00 & .75 & .27 \\
\hline $\begin{array}{l}\text { I do not care that background music is played while } \\
\text { performing written tasks }\end{array}$ & 2.37 & 1.24 & .14 & 2.00 & .15 & .27 \\
\hline
\end{tabular}

The students' attitude towards background music is positive if it affects their mood positively $(r=0.50$; $p<0.01)$, stimulates them to work $(r=0.29 ; p<0.01)$ and helps them performing tasks $(r=0.34$; $p<0.01)$. Some students, on the other hand, have a very strong negative attitude towards background music if it hinders them from focusing on work $(r=0.33 ; p<0.01)$.

\section{Conclusions}

The analysis of study results found that there are two reasons why teachers might u se background music in the classroom. The first one is to improve classroom behaviour and atmosphere. The second one is to improve the quality and/or quantity of work.

One of the study questions was intended to find out how background music influences a student's wellbeing in the music lesson. The first group of statements identified how background music can influence the well-being of students. The study determined that although background music creates a positive mood for most students, it could create a very negative mood for some students, which in turn negatively affects their well-being. Students feel comfortable while performing written tasks with music played in the background if this music can calm them down and/or stimulate them to work. On the one hand the calming effect of music is important if the student is worried about the task, but on the other hand, if the student is unable to start the task, then background music can be useful to stimulate him or her to perform the task.

The second study question was intended to clarify students' perceptions about the impact of background music on the quality of performing a written task. The study found that students evaluated the fact that background music can help them performing written tasks correctly at a medium level. The students believe that background music helps them performing the tasks if it affects them positively, promotes them to concentrate and stimulates them to work. The study found that the same background music can help one student perform the task correctly, but at the same time can disturb another student.

The third study question identified the students' attitude towards background music. The study found that some students have a very positive attitude towards background music and other students have a very negative attitude towards it. While one student likes to listen to music played in the background, it is very disturbing for another student at the same time. This study identified a variety of views, which is based 
largely on the individual characteristics of each student. Based on the results obtained in this study, it would be useful in further studies to investigate the relationship between each student's individual characteristics and the influence of playing background music while performing written tasks in the music lesson.

\section{Bibliography}

1. Abdolmanafi-Rokni S.J., Ataee A.J. (2014). The Effect of Background Music on Vocabulary Recall and Retention of Children Learning English as A Foreign Language. International Journal of Basic Sciences \& Applied Research. 3(8), 491-495. Retrieved from https://pdfs.semanticscholar.org/e95c/68b6f23b72f0276e43f2b5c76c891c1bea4a.pdf

2. Cassidy G., MacDonald R.A.R. (2007). The effect of background music and background noise on the task performance of introverts and extraverts. Psychology of Music, 35(3), 517-537. doi: 10.1177/0305735607076444

3. Chen A.C., Wen C.S. (2015). The Effects of Background Music Style on Mathematical Computation and Reading Comprehension. International Journal for Innovation Education and Research, 3(12), 164-170. Retrieved from https://www.ijier.net/index.php/ijier/article/view/497

4. Cho H. (2015). Is Background Music a Distraction or Facilitator?: An Investigation on the Influence of Background Music in L2 Writing. Multimedia-Assisted Language Learning, 18(2), 37-58.

5. Davidson C.W., Powell L.A. (1986). The Effects of Easy-Listening Background Music on the On-TaskPerformance of Fifth-Grade Children. The Journal of Educational Research, 80(1), 29-33. doi: 10.1080/00220671.1986.10885717

6. Decker-Voigt H.H. (1991). Aus der Seele gespielt. Eine Einführung in Musiktherapie. München: Wilhelm Goldmann.

7. DeMers A.S. (1996). The Effect of Background Music on Reading Comprehension Test Scores. (Master's Theses, The College at Brockport State University of New York, Brockport). Retrieved from http://digitalcommons.brockport.edu/ehd_theses/111

8. Furnham A., Strbac L. (2002). Music is as distracting as noise: the differential distraction of background music and noise on the cognitive test performance of introverts and extraverts. Ergonomics, 45(3), 203-217. doi: 10.1080/00140130210121932

9. Gillespie C.W., Glider K.R. (2010). Preschool teachers' use of music to scaffold children's learning and behaviour. Early Child Development and Care, 180(6), 799-808. doi: 10.1080/03004430802396530

10. Griffin M. (2015). Do you play background music in your classroom? Retrieved from https://mdgriffin63.wordpress.com/2015/02/16/do-you-play-background-music-in-your-classroom/

11. Hallam S.P., Price J., Katsarou G. (2002). The Effects of Background Music on Primary School Pupils' Task Performance. Educational Studies, 28(2), 111-122. doi: 10.1080/03055690220124551

12. Jucan D., Simion A. (2015). Music background in the classroom: its role in the development of socialemotional competence in preschool children. Procedia - Social and Behavioral Sciences, 180, 620-626. doi: 10.1016/j.sbspro.2015.02.169

13. Lee Y., Welch G.F. (2017). Teachers' Perceptions about the Use of Background Music in Preschool Free Play Time. Asia-Pacific journal of research in early childhood education, 11(2), 85-106. doi: 10.17206/apjrece.2017.11.2.85

14. Lehmann J.A.M., Seufert T. (2017). The Influence of Background Music on Learning in the Light of Different Theoretical Perspectives and the Role of Working Memory Capacity. Frontiers in Psychology. 8(1902). doi: 10.3389/fpsyg.2017.01902

15. Manthei M., Kelly S.N. (1999). Effects of Popular and Classical Background Music on the Math Test Scores of Undergraduate Students. Retrieved from http://music.arts.usf.edu/rpme/effects.htm

16. Rauduvaite A. (2018). The Educational Aspects of Integrating Popular Music into Lessons. In V. Dislere (Ed.), The Proceedings of the International Scientific Conference Rural Environment. Education. Personality (REEP), 11. Jelgava: Latvia University of Life Science and technologies, 94-100. doi: 10.22616/REEP.2018.011

17. Savan A. (1999). The Effect of Background Music on Learning. Psychology of Music, 27(2), 138-146. doi: $10.1177 / 0305735699272005$

18. Strachan D.L. (2015). The Space between the Notes: The Effects of Background Music on Student Focus. (Master Thesis, St. Catherine University, Minnesota). Retrieved from https://sophia.stkate.edu/maed/118

19. Szentgyorgyi E.A. (2015). Impact of music on student achievement. (Master's Project, State University of New York at Fredonia, New York). Retrieved from http://hdl.handle.net/1951/65757

20. White K.N. (2007). The Effects of Background Music in the Classroom on the Productivity, Motivation and Behavior of Fourth Grade Students. (Master Thesis in Education, Columbia College, South Carolina). Retrieved from https://eric.ed.gov/?id=ED522618

21. Zilgalve M.V. (2003). Funkcionālā mūzika dzīves skaistumkopšanā [Functional music in the beauty of life]. Müzikas psihologija, 8, 59-61. (in Latvian) 